\title{
PERANCANGAN MEDIA PEMBELAJARAN ENGLISH GRAMMAR BERBASIS ANDROID ANDROID BASED ENGLISH GRAMMAR LEARNING MEDIA
}

\author{
Mahendar Dwi Payana ${ }^{1}$, Harastha Pramunsyie ${ }^{2}$, Siti Maziah Aini ${ }^{3}$ \\ Universitas Ubudiyah Indonesia, \\ Jl. Alue Naga, Tibang. Kec. Syiah Kuala, Banda Aceh, Indonesia, 23114 \\ email:mahendar@uui.ac.id, haras@yahoo.com
}

\begin{abstract}
ABSTRAK
Pesatnya perkembangan teknologi dan kecanggihan multimedia menjadi dasar pembuatan media pembelajaran english grammar ini. Ide ini didapat karena pentingnya grammar dalam segala aspek berbahasa Inggris yaitu bahasa internasional. Kurangnya minat dalam pembelajaran tata bahasa inggris ini, serta efisiensi waktu tanpa perlu membeli buku yang dapat diakses kapanpun dan dimanapun menjadi bahan pokok utama penelitian ini. Perancangan aplikasi ini menggunakan bahasa pemrograman JAVA sebagai algoritma serta bahasa pemrograman XML sebagai Bahasa yang membentuk interface aplikasi. Aplikasi ini memuat topik materi dari the basic part of speech, the sixteen of tenses, passive voice dan tips dengan tampilan user friendly. Hasil Penilitian ini dapat menjadi alternative media pembelajaran dalam peningkatan aspek pembelajaran english grammar.
\end{abstract}

Kata Kunci : Android, English Grammar, JAVA, XML

\begin{abstract}
The rapid development of multimedia technology and sophistication as a cornerstone for this medium of learning english grammar. This idea gained because of the importance of grammar in all aspects of English is an international language. Lack of interest in learning English grammar, as well as time efficiency without the need to buy a book that can be accessed anytime and anywhere be the main staple of this research. The design of these applications using JAVA programming language as algorithms and programming language $X M L$ as the language that forms the application interface. This application includes subject matter of the basic part of speech, the sixteen of tenses, passive voice and tips by the display user friendly. This research results can be an alternative medium of learning in improving aspects of learning english grammar.
\end{abstract}

Keyword : Android, English Grammar, JAVA, XML

\section{PENDAHULUAN}

\section{Latar Belakang}

Dewasa ini masih ada yang tidak bisa mempelajari grammar Bahasa Inggris. Yang umumnya sulit menerapkan grammar secara tepat baik dalam kalimat tulis maupun lisan. Hal ini dikarenakan banyaknya aturan dalam grammar Bahasa Inggris. Sebut saja Tenses dalam Bahasa Inggris yang berjumlah 16 dan berbagai aturan lain-lain yang tidak jarang membingungkan dan rumit bagi sebagian besar orang. Selain itu, tata bahasa dalam Bahasa Indonesia dan Bahasa Inggris yang sangat berbeda juga menjadikan grammar Bahasa Inggris sulit dimengerti.
Oleh karena pentingnya bahasa universal dunia ini, pemerintah menjadikan Bahasa Inggris sebagai salah satu kurikulum wajib dari tingkat SD hingga perguruan tinggi, dalam pelamaran kerja dengan posisi yang bagus tak jarang diminta lancar berbahasa Inggris, terlebih lagi, belajar grammar akan sangat bermanfaat bagi anda yang akan menghadapi berbagai ujian Bahasa Inggris seperti TOEFL, TOEIC atau IELTS.

Berdasarkan uraian di atas akan pentingnya pembelajaran grammar bahasa inggris maka penelitian ini mengusulkan pembuatan media pembelajaran tentang English Grammar dalam 
bentuk mobile berbasis android yang dapat digunakan bagi para pelajar, mahasiswa ataupun semua kalangan yang memerlukan informasi dan pembelajaran tentang Grammar dalam Bahasa Inggris. Perancangan aplikasi ini menggunakan Bahasa pemograman JAVA dan Genymotion sebagai virtual device yang berperan penting dalam kelancaran uji coba aplikasi english grammar ini, serta dilakukan modifikasi desain pada interface, background dan color yang menggunakan bantuan CorelDRAW x7 dalam pembuatannya. Hasil penilitian dapat menjadi alternative media pembelajaran dalam peningkatan aspek pembelajaran english grammar.

\subsection{Rumusan Masalah}

Berikut ini merupakan rumusan masalah yang ada pada latar belakang di atas sebagai berikut

1. Bagaimana mengatasi dalam memudahkan pembelajaran english grammar.

2. Bagaimana meningkatkan minat para pengguna dalam mempelajari English grammar dalam kesehariannya.

\subsection{Batasan Masalah}

Dalam pembuatan penelitian ini memiliki beberapa batasan masalah antara lain :

1. Menampilkan dan berfokus pada topiktopik dasar pembelajaran english grammar diantaranya, adalah :
a. The Basic Part Of Speech
b. The Sixteen Of Tenses
c. Passive Voice

2. Aplikasi ini tidak mengutamakan animasi gerak, video, tetapi berupa teks dan audio hanya pada contoh.

\subsection{Tujuan Penelitian}

Adapun tujuan penelitian ini adalah :

1. Merancang aplikasi yang menarik untuk dapat dijadikan media pembelajaran bagi pengguna tentang english Grammar.

2. Membuat dan menampilkan suatu penjelasan tentang english grammar yang menarik, tidak membingungkan, dan mudah dimengerti dengan menggunakan android.

\subsection{Manfaat Penelitian}

Adapun tujuan penelitian ini adalah :

1. Bagi penulis khususnya, Dapat lebih memahami bagaimana proses-proses dalam merancang aplikasi android pembelajaran English grammar serta menerapkan pengetahuan dan keterampilan yang diperoleh di bangku kuliah.

2. Bagi Perguruan Tinggi, penelitian ini diharapkan dapat memberikan manfaat berupa sumbangan ilmu pengetahuan.

3. Bagi pengguna, diharapkan dapat membantu dalam meningkatkan pemahaman dan kemudahan dalam mempelajari english grammar.

4. Meningkatkan efektifitas dalam perkembangan teknologi khususnya dalam bidang pendidikan.

\section{TINJAUAN PUSTAKA}

\subsection{Media Pembelajaran}

Media pembelajaran adalah alat bantu proses belajar, yaitu meliputi alat bantu guru dalam mengajar serta sarana pembawa pesan dari sumber belajar ke penerima pesan belajar (siswa). Sebagai penyaji dan penyalur pesan, media belajar dalam hal-hal tertentu bisa mewakili guru menyajikan informasi belajar kepada siswa. Media pembelajaran juga merupakan segala sesuatu yang digunakan untuk menyalurkan pesan serta dapat merangsang pikiran, perasaan, perhatian, dan kemauan si belajar sehingga dapat mendorong terjadinya proses belajar yang disengaja, bertujuan, dan terkendali [6]. Maka media pembelajaran menempati posisi yang cukup penting sebagai salah satu komponen sistem pembelajaran. Tanpa media, komunikasi tidak akan terjadi dan proses pembelajaran sebagai proses komunikasi juga tidak akan bisa berlangsung secara optimal.[7]

\subsection{English Grammar}

Grammar merupakan tata bahasa yang wajib dipelajari dalam kelancaran bicara dan menjelaskan setiap arti dari setiap kalimat. Grammar juga merupakan sekumpulan aturan yang mengatur bagaimana setiap kata dalam bahasa Inggris dapat digabungkan menjadi sebuah kalimat yang baku untuk menjelaskan sebuah bahasa yang bermakna.[3]

\subsection{Android}

Android sebagai sebuah sistem, adalah sistem operasi berbasis Java yang berjalan pada kernel 2.6 Linux. Aplikasi Android yang dikembangkan menngunakan Java dan mudah menyesuaikan ke platform baru. Android merupakan satu kumpulan lengkap perangkat 
lunak yang dapat berupa sistem operasi, middleware, dan aplikasi kunci perangkat mobile. [1]

Android terdiri dari satu tumpukan yang lengkap mulai dari boot loader, device driver, fungsi-fungsi pustaka, hingga perangkat lunak API (Applicaton Programming Interface), termasuk aplikasi SDK (Software Development Kit). Jadi, Android adalah sistem operasi bergerak (mobile operating system) yang mengadopsi sistem operasi Linux, namun telah dimodifikasi.[2]

\subsection{Sistem Arsitektur Android}

1. Applications

2. Applications Framework

3. Libraries

4. Android Runtime

5. Linux Kernel

tingkatan-tingkatan sistem operasi Android dapat di lihat pada Gambar 2.1.

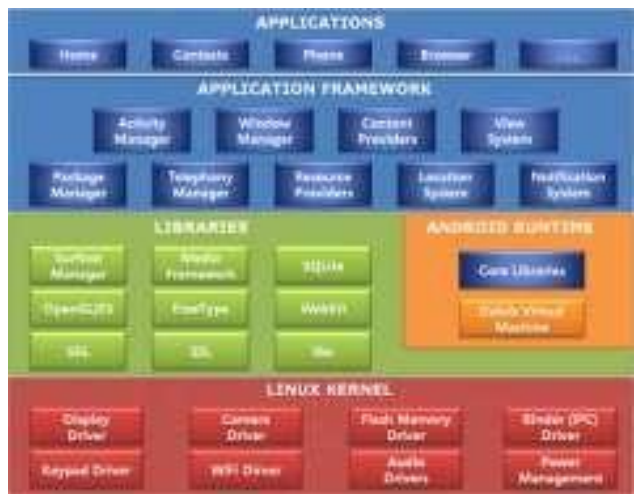

Gambar 2.1 Sistem Arsitektur Android

\section{$2.5 J a v a$}

Java adalah suatu bahasa pemrograman yang dapat dijalankan di berbagai komputer termasuk telepon genggam. Bahasa pemrograman ini awalnya dibuat oleh James Gosling saat itu masih bergabung di Sun Microsystems, saat ini merupakan bagian dari Oracle, dan dirilis pada tahun 1995. Bahasa ini banyak mengadopsi sintaksis yang terdapat pada bahasa pemrograman $\mathrm{C}$ dan $\mathrm{C}++$ namun lebih disederhanakan. Aplikasiaplikasi berbasis Java umumnya dikompilasi ke dalam p-code (bytecode) dan dapat dijalankan pada berbagai mesin virtual Java (JVM).[4]

\subsection{Android studio}

Android studio adalah lingkungan pengembangan Android baru berdasarkan Intellij IDE yang bisa digunakan untuk pengembangan aplikasi android. Android Studio menyediakan alat pengembang terintegrasi untuk pengembangan dan debugging. IDE nya yang bernama Android Studio dan Android SDK tools. Android studio merupkan sebuah IDE untuk Android Development yang diperkenalkan oleh Google. Android studio menggunakan Gradle untuk memanajemen project, Gradle merupakan Build Automation Tool. Peralihan ke sistem manajemen berbasis Gradle ini memberikan fleksibilitas yang lebih besar pada proses pembangunannya. Android Studio menggunakan Gradle sebagai build environment.[5]

\subsection{Android SDK (Software Development}

\section{Kit)}

Android SDK merupakan tool bagi para programmer yang ingin mengembangkan aplikasi berbasis android yang menggunakan bahasa pemrograman java. Pada saat ini SDK telah menjadi alat bantu android untuk mengembangkan aplikasi berbasis android. SDK bersifat gratis dalam penggunaannya dan bebas anda distribusikan karena sistem operasi android bersifat open source (kode terbuka).

\section{METODE PENELITIAN}

\subsection{Metode Penelitian}

Pada perancangan aplikasi ini penelitian menggunakan menggunakan metode deskriptif dalam proses yang bersifat mengumpulkan, menyusun, dan mengklarifikasikan pembagian data yang terkumpul dalam pengembangan aplikasi sesuai dengan keadaan yang diamati. Metode ini bertujuan untuk memberikan gambaran secara sistematis dan akurat menurut data-data yang di kumpulkan sehingga menjadikan data yang terangkum merupakan sebuah informasi yang saling berkaitan satu sama lainnya serta beralasan sesuai dengan keadaan yang sebenarnya.

\subsection{Alur Penelitian}

Alur kerja penilitian ini adalah perancangan sistem informasi. Dimana hasil akhirnya adalah berupa aplikasi pembelajaran english grammar berbasis android. Tahap awal penilitian di mulai dengan melakukan studi literatur mempelajari buku-buku dan hasil penilitian sejenis yang pernah di lakukan sebelumnya untuk mendapatkan landasan teori mengenai penilitian yang akan di teliti. Kemudian di lakukan analisa sistem yang akan di rancang agar pemakaian sistem benarbenar sesuai dengan kebutuhannya. Dapat dilihat pada Gambar 3.2. 


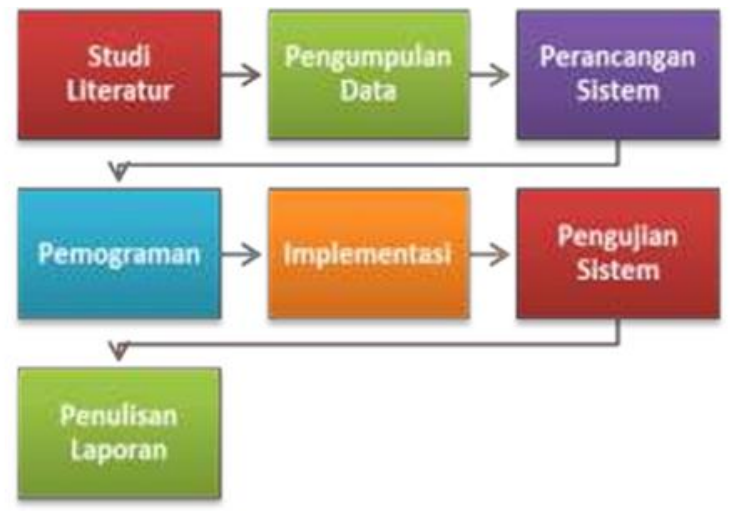

Gambar 3.2 Diagram Alur Penelitian

\subsection{Metode Pengumpulan Data}

Didalam penelitian ini digunakan 3 teknik pengumpulan data untuk memperoleh data dan informasi yang dibutuhkan. Adapun teknik yang digunakan dalam penelitian ini mencakup observasi lapangan, wawancara, dan studi literatur.

\subsection{Mekanisme Pengujian}

Mekanisme pengujian ini sendiri memiliki beberapan aspek yang akan diuji coba pada keseluruhan aplikasi, berikut pengujiannya :

1. Tampilan Splash Screen

2. Tampilan Menu Utama

3. Tampilan Submenu Materi Part of Speech

4. Tampilan Submenu Materi Sixteen of Tenses

5. Tampilan Submenu Passive Voice

6. Tampilan Submenu Tips

7. Tampilan Detail Materi

8. Tampilan pada android JellyBean

9. Tampilan pada android Kitkat

Tampilan pada android lollipop

\subsection{Flowchart Rancangan Sistem Pada Menu Utama}

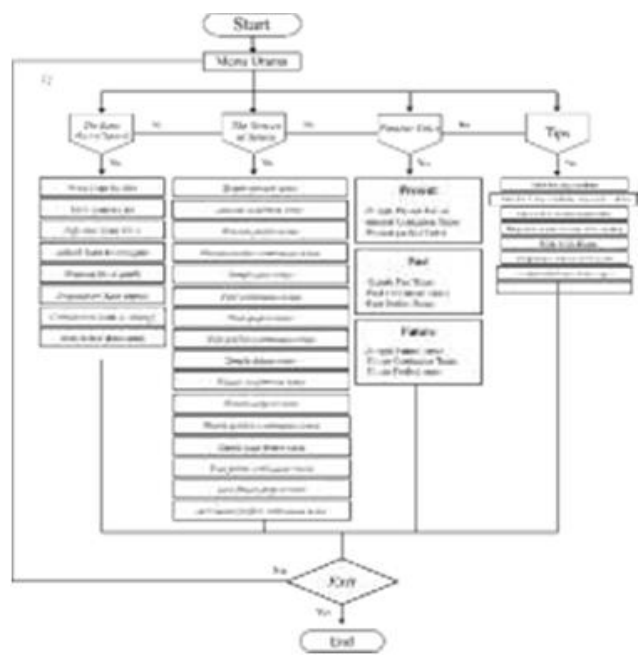

Gambar 3.3 Flowchart Aplikasi Menu Utama

\section{HASIL DAN PERANCANGAN}

\subsection{Hasil Penelitian}

Antarmuka merupakan tampilan dari aplikasi yang berperan sebagai media komunikasi antara program dengan pengguna. Aplikasi yang dibangun diharapkan menampilkan antarmuka yang mudah dipahami oleh pengguna. Berikut adalah hasil antarmuka pada aplikasi yang dibuat.

\subsubsection{Icon Aplikasi}

Pengujian aplikasi english grammar ini dilakukan dengan cara menginstal aplikasi ke smartphone berbasis android.

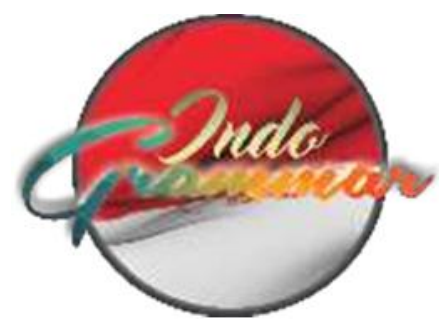

Gambar 4.1 Icon Aplikasi 


\subsubsection{Splash Screen}

Spalsh Screen adalah sebuah gambar yang muncul pertama pada saat aplikasi di jalankan, Splash Screen berisi informasi singkat tentang gambaran aplikasi yang ditampilkan secara cepat. Tampilan splashscreen seperti Gambar 4.2

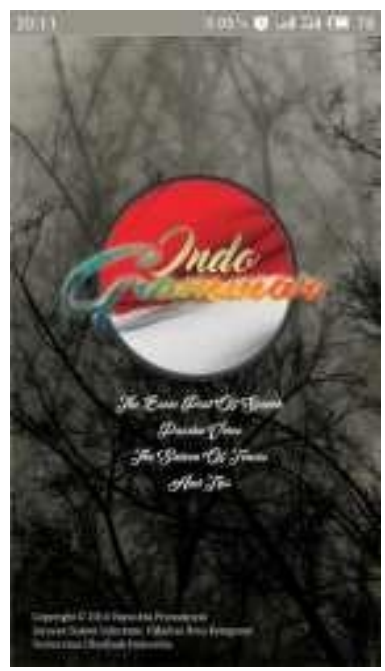

Gambar 4.2 Splash Screen

\subsubsection{Menu Utama}

Pada halaman utama akan tampak 4 button menu, yaitu:

1. Button Part of speech

2. Button Sixteen of Tenses

3. Button Passive Voice

4. Button Tips

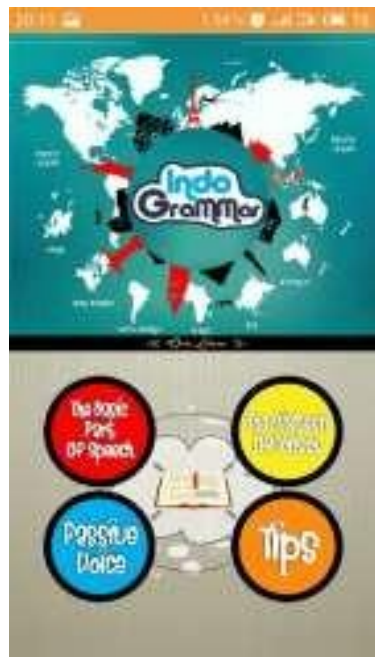

Gambar 4.3 Menu Utama

\subsubsection{SubMenu The Basic Part Of Speech}

Pada submenu the basic part of speech berisi delapan list (Noun, Verb, Adjective, Adverb,
Pronoun, Conjuntion, Preposition dan Interjection) setiap list yang dipilih pengguna, aplikasi akan menampilkan materi sesuai dengan pilihan pengguna. Tampilan submenu the basic part of speech seperti Gambar 4.4.

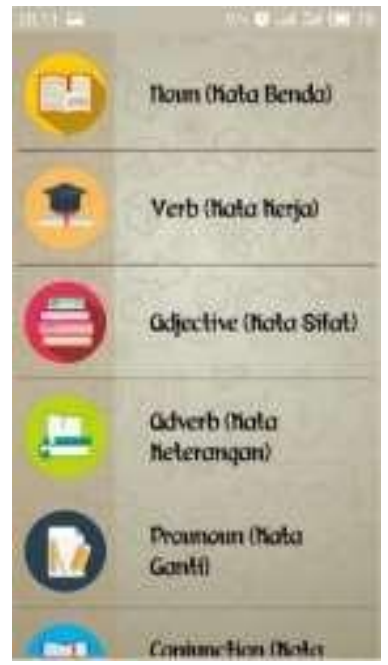

Gambar 4.4 Submenu The Basic Part Of Speech

\subsubsection{SubMenu The Sixteen Of Tenses}

Pada submenu the sixteen of tenses berisi enam belas list (Present, Present Continuous, Present Perfect, Present Perfect Continuous, Past, Past Continuous, Past Perfect, Past Perfect Continuous, Future, Future Continuous, Future Perfect, Future Perfect Continuous, Past Future, Past Future Perfect, Past Future Perfect Continuous) setiap list yang dipilih pengguna, aplikasi akan menampilkan materi sesuai dengan pilihan pengguna. Tampilan submenu the sixteen of tenses seperti Gambar 4.5.

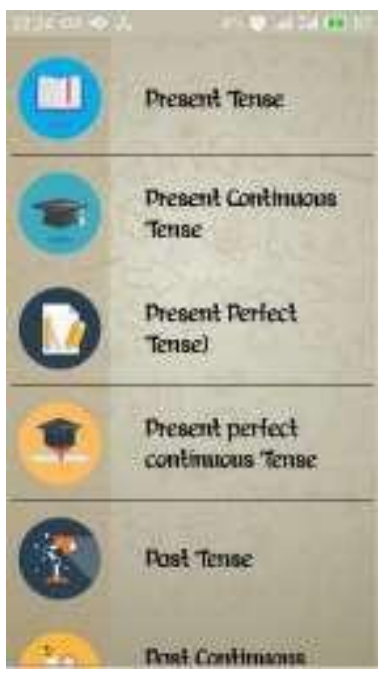

Gambar 4.5 Submenu The Sixteen Of Tenses 


\subsubsection{SubMenu Passive Voice}

Pada submenu passive voice berisi sembilan list (Present, Present Continuous, Present Perfect, Simple Past, Past Continuous, Past Perfect, Simple Future, Future Continuous, Future Perfect) setiap list yang dipilih pengguna, aplikasi akan menampilkan materi sesuai dengan pilihan pengguna. Tampilan submenu passive voice seperti Gambar 4.6.

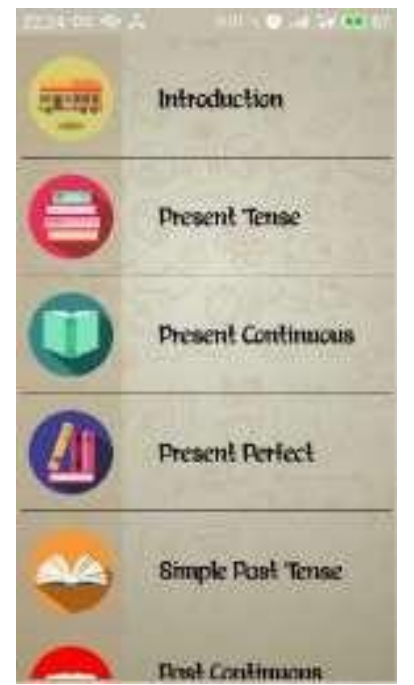

Gambar 4.6 Submenu Passive Voice

\subsubsection{SubMenu Tips}

Pada submenu tips berisi sembilan list (mulai dari yang sederhana, amati teks inggris atau lirik lagu, perbanyak latihan mengerjakan soal, menerapkan grammar dalam speaking, selalu sedia kamus, disiplin dan tidak mudah menyerah setiap list yang dipilih pengguna, aplikasi akan menampilkan materi sesuai dengan pilihan pengguna. Tampilan submenu tips seperti Gambar 4.7 .

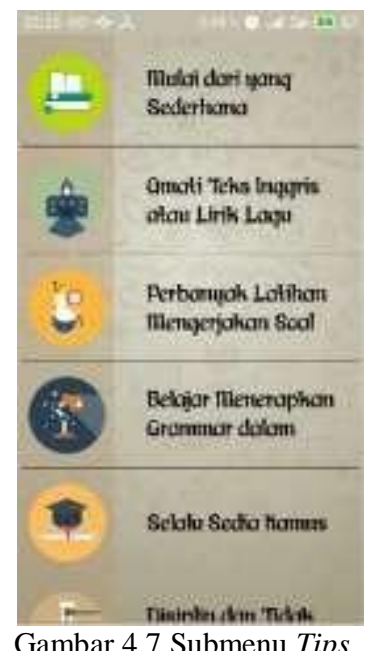

\subsubsection{Detail Materi}

Pada tampilan detail materi menampilkan informasi materi dalam sebuah penjelasan beserta cotoh yang menghasilkan suara. Pengguna dapat menekan setiap contoh yang ada untuk mendengar suara yang di hasilkan. Tampilan detail informasi seperti Gambar 4.8.

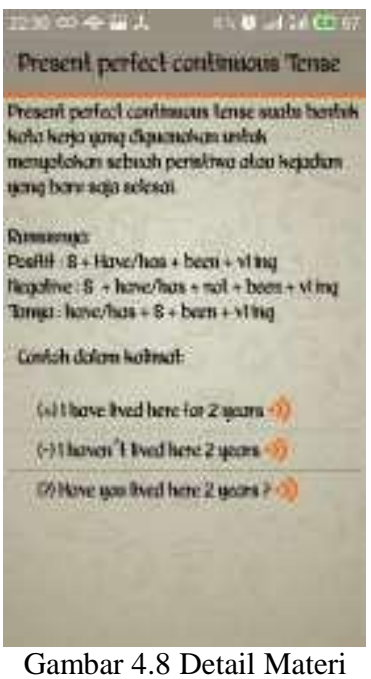

\section{KESIMPULAN DAN SARAN}

\subsection{Kesimpulan}

berdasarkan hasil perancangan dan pengimplementasian media pembelajaran English grammar berbasis android, yaitu :

1. Aplikasi telah dirancang berbasis android dan dikemas dengan tampilan user friendly yang dapat memudahkan pengguna khususnya mahasiswa kampus Universitas Ubudiyah Indonesia dalam meningkatkan english grammar.

2. Aplikasi merupakan suatu media pembelajaran dalam bidang grammar dengan menampilkan beberapa materi pokok umum yang dapat di pelajari.

3. Menurut hasil pengujian melalui kuisioner yang telah dibagian kepada responden, diperoleh kesimpulan bahwa aplikasi Indo Grammar berbasis smartphone android ini menarik, mudah dioperasikan, dan informasi yang disampaikan sesuai dengan kebutuhan, sehingga menjadi solusi dalam pembelajaran english grammar.

4. Aplikasi ini dapat berjalan dalam versi android tertentu seperti android jelly bean 4.1.2, 4.4 android kitkat dan android lollipop 5.1. 
Journal of Informatics and Computer Science Vol. 5 No. 2 Oktober 2019

Universitas Ubudiyah Indonesia

e-ISSN : 2615-5346

5. Diharapkan dengan adanya aplikasi ini dapat membantu pengguna dan mahasiswa untuk giat belajar grammar dengan mudah.

\subsection{Saran}

Saran yang dapat di rekomendasikan oleh penulis dalam menyelesaikan tugas akhir ini adalah sebagai berikut :

1. Aplikasi yang akan di kembangkan untuk kedepannya di harapkan dapat memaksimalkan bahan pembelajaran dalam materi grammar sehingga meningkatkan keinginan pengguna dalam pembelajarannya.

2. Aplikasi yang akan di kembangkan untuk selanjutnya di harapkan dapat di tambah fiturfitur yang menarik seperti button menu yang lebih banyak, desain yang lebih bagus, sehingga pengguna tidak bosan memakai aplikasi ini.

Demikian saran yang dapat penulis berikan, semoga saran tersebut bisa dijadikan sebagai bahan masukkan yang dapat bermanfaat bagi penulis khususnya dan umumnya bagi masyarakat luas.

\section{Daftar Pustaka}

[1] Akbarul Huda, Arif. 2013. 9 Aplikasi Android Buatan Sendiri. Yogyakarta : Andi Publisher.

[2] Dharma K, Ahmad. 2013. Kolaborasi Dahsyat Android Dengan php \& Mysql. Lokomedia. Yogyakarta: Lokomedia.

[3] Hafilia, Winda. 2011. "Perancangan Model Pembelajaran Tata Bahasa Inggris (English Grammar)" Medan.

[4] Kadir, Abdul. 2011. Algoritma \& pemrograman Menggunakan Java. Yogyakarta : Andi Publisher.

[5] Pradana, Andi. 2015. Pemograman aplikasi mobile Smartphone dan tablet pc berbasis android. Bandung.

[6] Pandiangan A, Dewi. 2013. "Perancangan Media Pembelajaran English Grammar Berbasis Web" Medan.

[7] Poldauf. 1948. Some Problems In The History of English Grammar Before 1800. Praha. 